University of Nebraska - Lincoln

DigitalCommons@University of Nebraska - Lincoln

1999

\title{
Studying Stress in Ecological Systems: Implications for Ecological Risk Assessment and Risk Management
}

Valery E. Forbes

University of Nebraska-Lincoln, veforbes@umn.edu

Follow this and additional works at: https://digitalcommons.unl.edu/biosciforbes

Part of the Pharmacology, Toxicology and Environmental Health Commons

Forbes, Valery E., "Studying Stress in Ecological Systems: Implications for Ecological Risk Assessment and Risk Management" (1999). Valery Forbes Publications. 7.

https://digitalcommons.unl.edu/biosciforbes/7

This Article is brought to you for free and open access by the Papers in the Biological Sciences at DigitalCommons@University of Nebraska - Lincoln. It has been accepted for inclusion in Valery Forbes Publications by an authorized administrator of DigitalCommons@University of Nebraska - Lincoln. 


\title{
Invited Feature
}

\author{
Studying Stress in Ecological Systems: Implications for \\ Ecological Risk Assessment and Risk Management ${ }^{1}$
}

In many of the world's habitats abiotic stress is a key force controlling the distribution and abundance of species. As a result of human activities, the role of abiotic stress appears to be increasing in many areas in the form of habitat alteration or destruction, chemical contamination, and large-scale climatic shifts. An important scientific goal, therefore, is to develop approaches for assessing and predicting damage to ecological systems arising from abiotic stress. Moreover, determining how interactions between human-caused stresses and natural environmental stresses impact biological systems is an active area of research. This Invited Feature highlights some of the main issues addressed during a conference held at Roskilde University, Denmark, in June 1997 on "Studying Stress in Ecological Systems: Pure and Applied Perspectives." I would like to express my sincere appreciation to all of the contributors for taking the opportunity to share their ideas in this forum.

In the first paper in this feature, Maltby demonstrates how studies of stress at lower levels of biological organization (e.g., molecular, biochemical) are critical for elucidating the mechanistic bases of the effects of stress on organisms, whereas studies of stress at higher levels of biological organization (e.g., population, assemblage) are key for understanding the consequences of stress on those ecological structures and functions that are the objects of protection and management. Thus, the importance of organism-level responses is to provide a pivotal point through which mechanistic understanding and ecological consequences of stress can be effectively linked.

Dao et al. offer a rare insight into the biochemical and molecular effects of toxicant stress on a single bacterial species and link these responses to effects on bacterial growth. Their work demonstrates how the application of molecular techniques can improve understanding of the mechanistic bases of stress responses in bacteria, a group of organisms of clear fundamental importance to the normal functioning of ecosystems and to the fate of xenobiotic chemicals in nature.

Variability in the responses of different populations of the same species to environmental stress is of interest in that it indicates the ability of organisms to acclimate or adapt to stressful circumstances and may help to explain why certain species are able to exploit stressful habitats whereas others are excluded. However, variability within species can prove problematic for interpreting the results of ecotoxicological tests, which provide the basis for risk assessment and management. Determining whether increased stress tolerance in exposed populations derives from environmental influences or whether it represents selection of stress-resistant genotypes is an important issue in this regard. Lam describes two types of experimental procedures, a controlled breeding approach and a mass-culture technique, that can be used to separate genetic and environmental causes of interpopulation variation in stress tolerance.

The idea that variability in the responses of organisms to stress may provide a useful tool for quantifying stress in natural populations is an intriguing and potentially promising suggestion. Callaghan and Holloway found that the variance in detoxification enzyme activity in two insect species increased upon transfer to a new food source, and the increase was particularly pronounced when the new food source was toxic. If the variance of phenotypic traits increases in response to stress, statistical detection by traditional approaches (e.g., ANOVA tests based on group means) will be impeded. If, as the authors suggest, the variance rather than or in addition to the mean

\footnotetext{
${ }^{1}$ Reprints of this 75 -page Invited Feature are available for $\$ 11.25$ each. Prepayment is required. Order reprints from the Ecological Society of America, Attention: Reprint Department, 2010 Massachusetts Avenue, N.W., Suite 400, Washington DC 20036.
} 
response is employed as a stress measure, detecting the effects of stress on key biological functions may be facilitated.

Interactions between human-caused stress and natural environmental variability are of practical relevance, for example, in the application of biomarkers as indicators of human-caused stress. Moreover, predicting the impacts of human-caused stresses on ecological systems requires understanding of how natural environmental factors, especially related to seasonal environmental fluctuations, are likely to exacerbate or ameliorate the impacts.

Nielsen et al. explored seasonal variability in detoxification enzyme activity of wolf spiders, which are important predators of insect pests and which are particularly sensitive to insecticide exposure in agricultural areas. Both the basal levels of enzyme activity and the inducibility of the enzymes in response to insecticide exposure showed substantial seasonal variation, particularly in relation to the period of hibernation. The results have important implications for selecting the timing of pesticide application so that impacts on the natural enemies of pest species are minimized.

Lyytikäinen-Saarenmaa examined the responses of Scots pine saplings to natural and artificial defoliation stress during early and late phases of the growing period. The results showed that the consequences of defoliation stress depended on the type of defoliation and the intensity of damage, as well as the timing of damage. These findings have practical implications for improving forest management strategies and for evaluating the severity of insect outbreaks.

Effects of both seasonal temperature and stress caused by trematode parasite infection on the bioaccumulation of two organic toxicants by a freshwater clam were examined by Heinonen et al. Their results showed rather complex interactions between the effects of temperature and parasite infection on toxicant body burdens attained by the clams and suggest that consideration of both of these factors may be pertinent for assessing the ecological risks associated with persistent organic pollutants.

Whereas the application of molecular and biochemical techniques can increase understanding of the mechanisms by which whole organisms are impaired, the application of population dynamics models can be employed to explore the mechanisms by which populations are impacted through stress effects operating on individuals. Hansen et al. applied demographic analysis to data derived from a life-table response experiment that was designed to test the effects of chemical stress on growth, reproduction, and survivorship of a polychaete worm. The results showed that the consequences of changes in each life-history trait for population dynamics depended on the starting value of population growth rate, on the extent to which each of the traits was impacted by toxicant stress, and on the specific life-history characteristics of the species under consideration.

Although quite powerful for linking individual-level responses to population-level impacts of environmental stress, a disadvantage of life-table response experiments is that they are labor intensive and time consuming. Sibly proposes a shortcut approach for assessing population-level impacts of stress that is particularly appropriate for simulating realistic population densities. Sibly points out that most of the life-table response experiments published to date have been carried out under conditions of low population density and that measurements made under such conditions may underestimate population stress responses. In order to achieve further insights into the effects of environmental stress on density-limited populations, Sibly recommends faster and more efficient techniques for measuring population growth rates and their associated confidence intervals.

The articles in this feature represent novel insights into the study of stress in different types of ecological systems and at different levels of biological organization. The contributions demonstrate how the effects of stress on natural systems can be effectively examined, how the mechanisms by which stress influences key biological processes can be elucidated, and how knowledge of the role of stress in ecological systems can be applied to solving practical problems. It is my sincere hope that this feature will provide inspiration to those involved in the scientific study of natural and anthropogenic stress as well as those involved in the practices of ecological risk assessment and management.

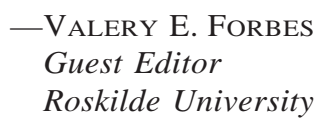

Key words: anthropogenic; biological hierarchy; biomarkers; population dynamics; variability. 